\title{
Dermatoglyphic characteristics of Chinese professional table tennis players
}

\author{
Feng TAI ${ }^{1}$ (D), Chao ZHENG ${ }^{1}$, Ye ZHANG ${ }^{1}$,Yilun $\mathrm{GAO}^{1 *}$, Xin $\mathrm{DENG}^{2 *}$
}

\begin{abstract}
To perform dermatoglyphics analysis and to explore the possible relationships between dermatoglyphic characteristics and sports level of Chinese table tennis players. A total of 92 Chinese professional table tennis players were recruited and divided into ordinary group and excellent group according to their levels. Their dermatoglyphic patterns on the palms and fingers were collected and statistically analyzed. Our results showed that the data revealed significant differences $(p<0.05)$ between the ordinary group and the excellent group in terms of atd angle, thenar eminence, total number of a-b ridges and double loop whorl, while no significant differences $(\mathrm{p}>0.05)$ were observed in concentric whorl, arch pattern and loop pattern. In conclusion, these findings may provide experimental evidence for the application of dermatoglyphic analysis as a tool for future selection of elite table tennis players.
\end{abstract}

Keywords: table tennis player; dermatoglyphic characteristics; athlete selection; physical growth; thenar eminence.

Practical Application: Dermatoglyphics analysis was used to explore the possible relationships between dermatoglyphic characteristics and sports level of Chinese table tennis players. We revealed significant differences between the ordinary group and the excellent group in terms of atd angle, thenar eminence, total number of a-b ridges and double loop whorl. These findings may provide experimental evidence for the application of dermatoglyphic analysis as a tool for future selection of elite table tennis players.

\section{Introduction}

Table Tennis, as the national sport of China, is widely accepted and popular in general public. The Chinese table tennis team has long dominated world table tennis and won numerous world championships, maintaining its supremacy status. The reasons for these admirable achievements can be summarized as not only excellent cultural inheritance and good sports management and guarantee systems, but also a well-established talent echelon and athlete selection mechanism. In this regard, selecting outstanding athletes and talented table tennis elites constitutes the key factor to ensure the long-term prosperity of the Chinese table tennis team. To achieve future high-level performance in sports competition, the successful establishment of scientific and reliable methods for talent athlete selection is urgently needed (Johnston et al., 2018; Abbott et al., 2005).

Dermatoglyphics originates from the extensive works on fingerprints and prints from the soles of the feet, physical growth, genetics, mass distribution as well as applied science (Lakshmana et al., 2017; Fournier \& Ross, 2016). It is well accepted that dermatoglyphy is an exposed genetic factor for human beings (Ho et al., 2016). The dermatoglyphy begin to grow gradually at the $13^{\text {th }}$ week of pregnancy and finish at about $19^{\text {th }}$ week. The dermatoglyphics studies first appeared in the medical field. Previous fundamental and clinical studies have shown that dermatoglyphics may serve as a possible biomarker in the neurodevelopment and mental disorders (Ahmed-Popova et al., 2014). Long-term clinical practice indicates that patients with

the same genetic diseases have the same shape of palm skin lines (Li \& Ji, 1995). This represents a deeper exploration into the interpretation of the biological code information of human, promoting the early detection and prevention of congenital diseases.

Additionally, dermatoglyphics can also serve as reliable strategy to assess the sports potential, physical quality and congenital diseases when correlating with human performance. Previous studies have found that the types and patterns of human dermatoglyphy are closely related to their health status, physical quality, sports potential, nerve types and IQ factors, including strength, endurance, speed, coordination, flexibility and other important qualities required for athletes in competitive sports (Shao, 1992; Maluly et al., 2020; Amaral et al., 2020; Karaagac et al., 2021). Dermatoglyphics featuring high stability have been applied to various sports as an auxiliary and valuable tool for athlete selection, including soccer, tennis, basketball, volley ball, track and field, etc (Yu \& Tai, 2012; Wang, 2005; Oliveira et al., 2018; Borin et al., 2012; Priyadarshini et al., 2016; Serhiyenko \& Lyshevska, 2013). In this study, we aimed to perform dermatoglyphics analysis and to explore the possible relationships between dermatoglyphic characteristics and sports level of Chinese table tennis players, the dermatoglyphic characteristics of 92 professional table tennis players were collected and analyzed. The combined results may provide experimental evidence for a feasible method to improve the success rate of selecting athletes of table tennis. 


\section{Materials and methods}

\subsection{Participants}

A total of 92 Chinese professional table tennis players from Liaoning team, Beijing team, Shandong team, Jiangxi team and Zhejiang team were recruited. According to their sports performance level, the athletes were divided into general group (including 66 athletes rated as first and second level athletes, 39 males and 27 females) and excellent group (including 26 capped players for the national team with higher athletic performance, 11 males and 15 females).

\subsection{Handprints collection}

Black ink was mixed with mineral water with a concentration ratio of 7:3. The subjects' hands covered with a sponge was dipped in the mixed ink. The subjects were required to hold up their palms and make the five fingers apart, press palms on the white paper firstly, and then to raise palms and press each finger in turn. According to the flatness of the palm, subjects were asked to press the metacarpophalangeal joint with the other auxiliary hand to make the texture of hands and fingers clearly printed on paper. During the whole process of handprints collection, it is worthy to note that the fingers should rotate at a constant speed and cannot be shifted or printed repeatedly in one place. The handprint should be printed on the corresponding finger position to avoid confusion during the measurement and analysis. Finally, the subjects wrote their names at the top right corner of the hand-printing paper to ensure the authenticity of the information, and sign informed consent form.

\subsection{Data collection and analysis}

After collecting information, magnifying glass, ruler, protractor and other devices were used to carefully measure the palm prints and fingerprints of the subjects. The atd angle, real dermatoglyph of thenar eminence, total number of $a-b$ ridges, concentric whorl, arch pattern, loop pattern and double loop whorl of fingers, were selected as dermatoglyphic indices and recorded respectively (Figure 1). Magnifying glass was used to magnify the small lines of handprints, thus assuring clear display of the type and number of prints. The two lines of the atd angle between palm lines were drawn with ruler, followed by the measurement of angle degree using protractor.

\subsection{Statistical analysis}

The independent sample $T$ test was performed for statistical analysis using SPSS24.0 software. All data were presented as mean \pm standard error of mean (SEM). The statistical analysis results were considered significantly correlated when $p<0.05$.

\section{Results and discussion}

\section{1 atd angle}

The atd angle is the angle formed when $t$ point is the vertex and $a$ point is connected with $d$ point. Point $a$ is about $1 \mathrm{~cm}$ below the base of the index finger of the palm. Point $d$ is about

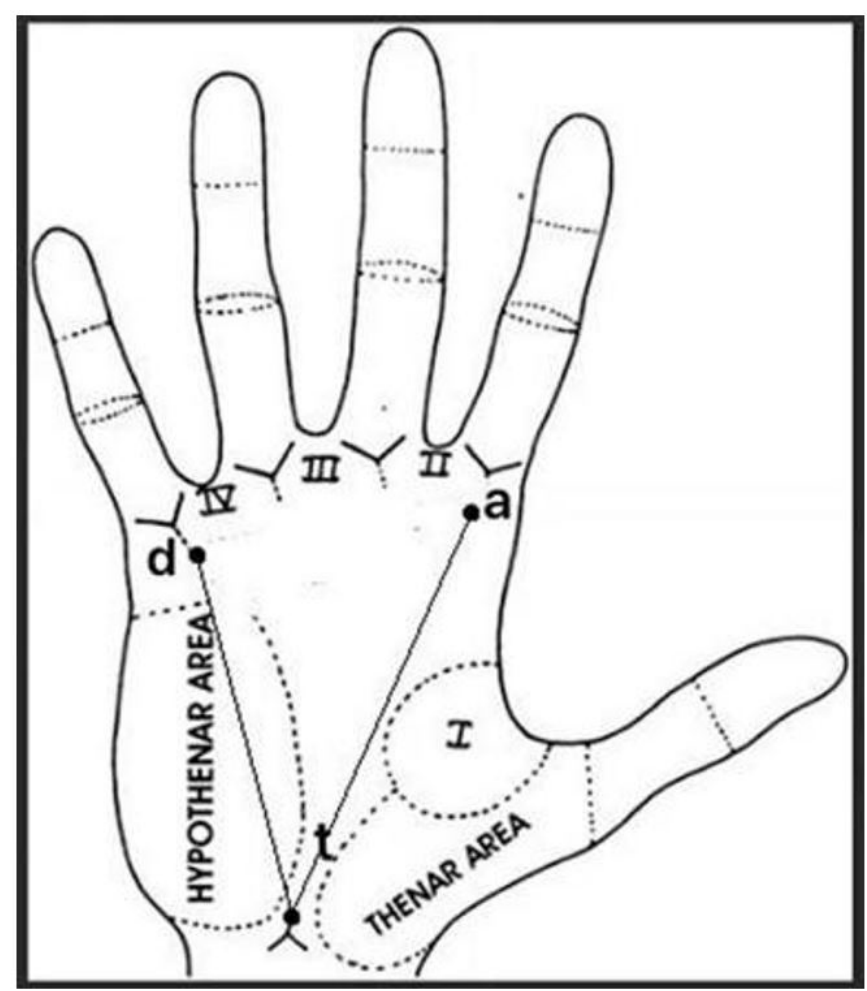

Figure 1. The abridged general view of thenar eminence, atd angle, and the location of point $\mathrm{a}, \mathrm{b}, \mathrm{c}, \mathrm{d}$ and $\mathrm{t}$.

$1 \mathrm{~cm}$ below the base of the little finger of the palm. Point $t$ is at the base of the palm, about $1-2 \mathrm{~cm}$ above the wrist (Figure 1). In dermatoglyphics studies, the atd angle of most normal individuals falls within the range of $35-40^{\circ}$. The atd angle of some patients with congenital hereditary disease featuring defective neural development of the brain, such as Down's syndrome, Patau's syndrome, and XO syndrome etc., can reach above $70^{\circ}$ (Shao, 1992). In this study, we found that the athletes in excellent group had a smaller average atd angle compared to that of ordinary group $\left(37.31 \pm 2.471^{\circ}\right.$ vs $\left.40.46 \pm 1.968^{\circ}, \mathrm{p}<0.01\right)$ (Table 1$)$. For example, one of the capped athletes of national team is featured with a $35.9^{\circ}$ atd angle of left hand, a $36.3^{\circ}$ atd angle of right hand, and an average of $36.1^{\circ}$ atd angle (Figure 2). Previous studies have indicated that high mental level and response speed are of necessity for table tennis atheletes, who also show smaller atd angle (Supplementary Table S1). Our data further confirmed that excellent Chinese table tennis players have a higher mental level, which helps to resist pressure and strain and allows them to effectively control the rhythm of the game.

\subsection{Thenar eminence}

The type of real dermatoglyphy of thenar eminence belongs to variable dermatoglyphy, which is usually associated with the body's cardiopulmonary function and certain genetic diseases. In 1989, Shao et al.have found that the incidence of real dermatoglyph of thenar eminence was $10 \%$ in the ordinary population, while it reduced to only about $2.5 \%$ in the high-level athletes (Shao, 1989). The statistical results of the real dermatoglyph of thenar 

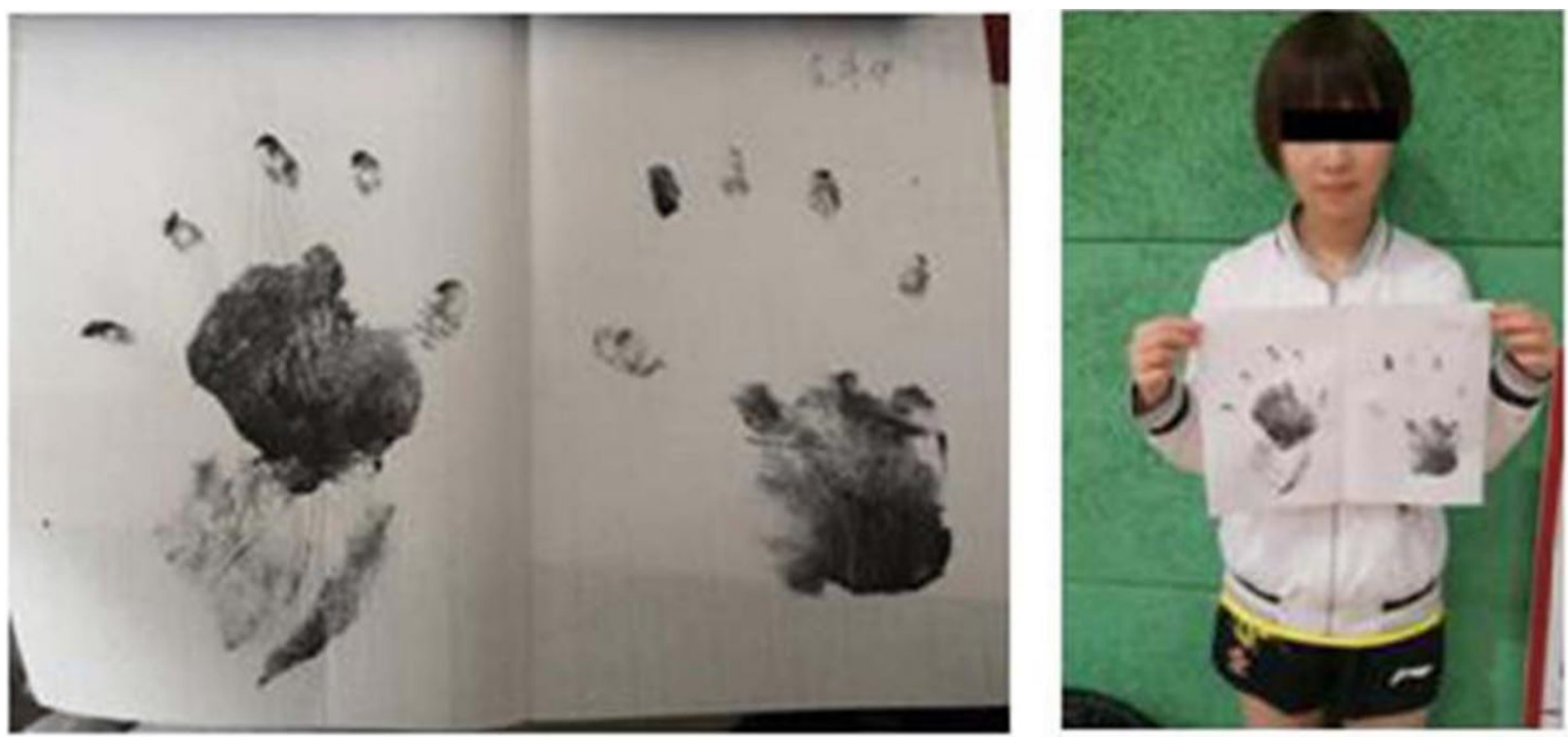

Figure 2. Sample handprints of one of the capped athletes of national team.

Table 1. The comparison of atd angle between excellent group and ordinary group.

\begin{tabular}{cccccc}
\hline Group & $\mathrm{N}$ & $\mathrm{M} \pm \mathrm{SD}$ & $\mathrm{T}$ & $\mathrm{SIN}$ & $P$ \\
\hline Excellent & 26 & $37.31 \pm 2.471$ & -4.214 & 0.000 & 0.01 \\
Ordinary & 66 & $40.46 \pm 1.968$ & & & \\
\hline
\end{tabular}

$\mathrm{N}=$ the number of the sample; $\mathrm{M} \pm \mathrm{SD}=$ mean value \pm standard deviation; SIN = significance (two-tailed); $P<0.05=$ Significant difference; $P<0.01=$ very significant difference; $P>0.05=$ no significant difference (similarly hereinafter)

Table 2. The comparison of real dermatoglyph of thenar eminence between excellent group and ordinary group.

\begin{tabular}{ccc}
\hline Group & $\begin{array}{c}\text { Total } \\
(\mathrm{N})\end{array}$ & Real dermatoglyph of thenar eminence $(\mathrm{N})$ \\
\hline Excellent & 26 & 0 \\
Ordinary & 66 & 0 \\
\hline
\end{tabular}

eminence and the dermatoglyph of the first interphalangeal region were also reported, which revealed that the incidence of real dermatoglyph of thenar eminence was lower in the elite weightlifter $(9.03 \pm 2.22)$ than in the ordinary population $(19.00 \pm 1.21)$, and the value was even zero in the swimmer and male gymnasts (Zhang \& Li, 2008). In fact, the incidence of real dermatoglyph of thenar eminence is very low in the high-level athletes no matter what kind of sports events they engage in. Among the 376 national athletes in track and field team, only one javelin thrower has the real dermatoglyph of thenar eminence (Yu \& Tai, 2012). In this study, as shown in Table 2, we found no real dermatoglyph of thenar eminence among Chinese table tennis players in both the excellent and the ordinary groups, indicating a normal cardiorespiratory condition and absence of genetic disease.

\section{$3.3 a-b$ ridges}

The number of a-b ridges is the total number of lines between point $a$ at about $1-2 \mathrm{~cm}$ below the base of the index finger of the palm and point $b$ at about $1-2 \mathrm{~cm}$ below the base of the middle finger of the palm. The number of a-b ridges directly affects the movement and reaction speed, which is very important in competition and training for athletes (Qiu, 2015). Also, we found that it is closely related to the atd angle. The smaller atd angle relates to the higher innate mental level, while the smaller number of $a-b$ ridges relates to the faster movement and reaction speed. The statistical analysis of this study reveals that the atd angle in the excellent group was smaller than that in the ordinary group, accompanied with smaller number of a-b ridges. It can be concluded that the high mental level is partly related to the movement and reaction speed. In this study, Table 3 shows that there is a significant difference $(p<0.01)$ in the total number of a-b ridges between the excellent group $(41.23 \pm 3.143)$ and ordinary group (46.48 \pm 2.472$)$, suggesting faster movement and reaction speed in the excellent group.

\subsection{Concentric whorl}

As a common dermatoglyphy on human fingers (Figure 3) which is generally related to the strength quality of athletes (Tian, 2006), concentric whorl features many circular ridges around the center, and usually two trifurcation points on the left and right sides. The more concentric whorl represents the more prominent strength potential. The strength quality is closely related to the type of muscle fiber, the size of muscle crosssection and the coordination, as well as effective development of various muscles. In this study, the dermatoglyphy of one of China's elite table tennis player shown in Figure 4 indicates that there is no significant difference in the number of concentric whorl between the athletes in excellent group and those in 
ordinary group (Table $4, \mathrm{p}>0.05$ ), indicating the absence of strength quality difference between the two groups.

\subsection{Arch pattern}

Arch pattern is one kind of arched dermatoglyphy of human finger (Figure 5), in which the lines move from left to right and the middle part raises, with no trifurcation points and center. It can be divided into two kinds of arch patterns according to the shape, the flatter and higher ones are the flat arch and tented arch, respectively. Previous report revealed that the number of arch pattern is in negative correlation with endurance quality (Wang, 2006). Human endurance is
Table 3. The comparison of total number of a-b ridges between excellent group and ordinary group.

\begin{tabular}{cccccc}
\hline Group & $\mathrm{N}$ & $\mathrm{M} \pm \mathrm{SD}$ & $\mathrm{T}$ & $\mathrm{SIN}$ & $P$ \\
\hline Excellent & 26 & $41.23 \pm 3.143$ & -4.214 & 0.002 & $<0.01$ \\
Ordinary & 66 & $46.48 \pm 2.472$ & & & \\
\hline
\end{tabular}

Table 4. The comparison of concentric whorl between excellent group and ordinary group.

\begin{tabular}{cccccc}
\hline Group & $\mathrm{N}$ & $\mathrm{M} \pm \mathrm{SD}$ & $\mathrm{T}$ & $\mathrm{SIN}$ & $P$ \\
\hline Excellent & 26 & $2.41 \pm 3.537$ & 0.351 & 0.852 & $>0.05$ \\
Ordinary & 66 & $2.62 \pm 3.812$ & & & \\
\hline
\end{tabular}
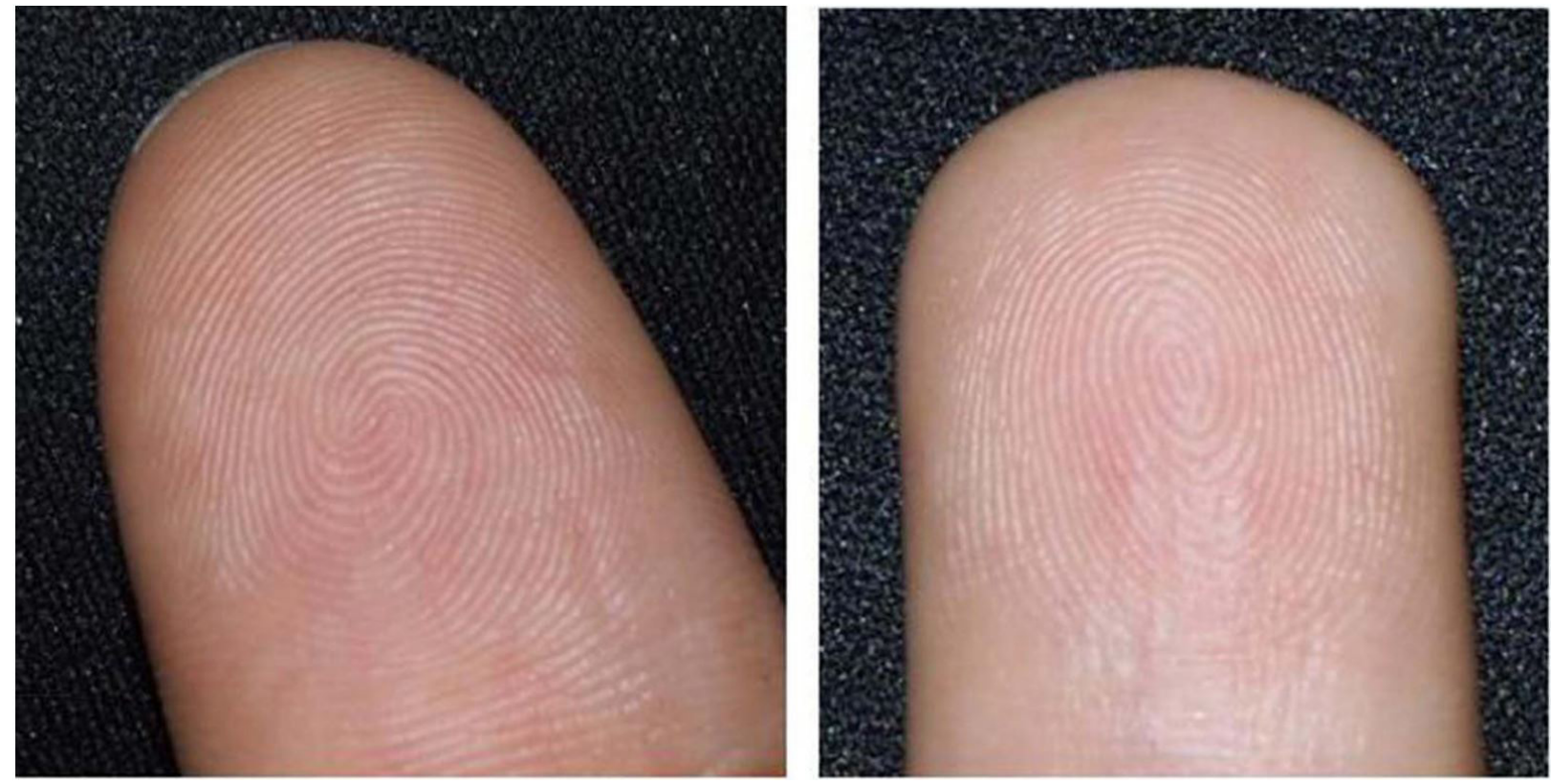

Figure 3. Typical image of concentric whorl.
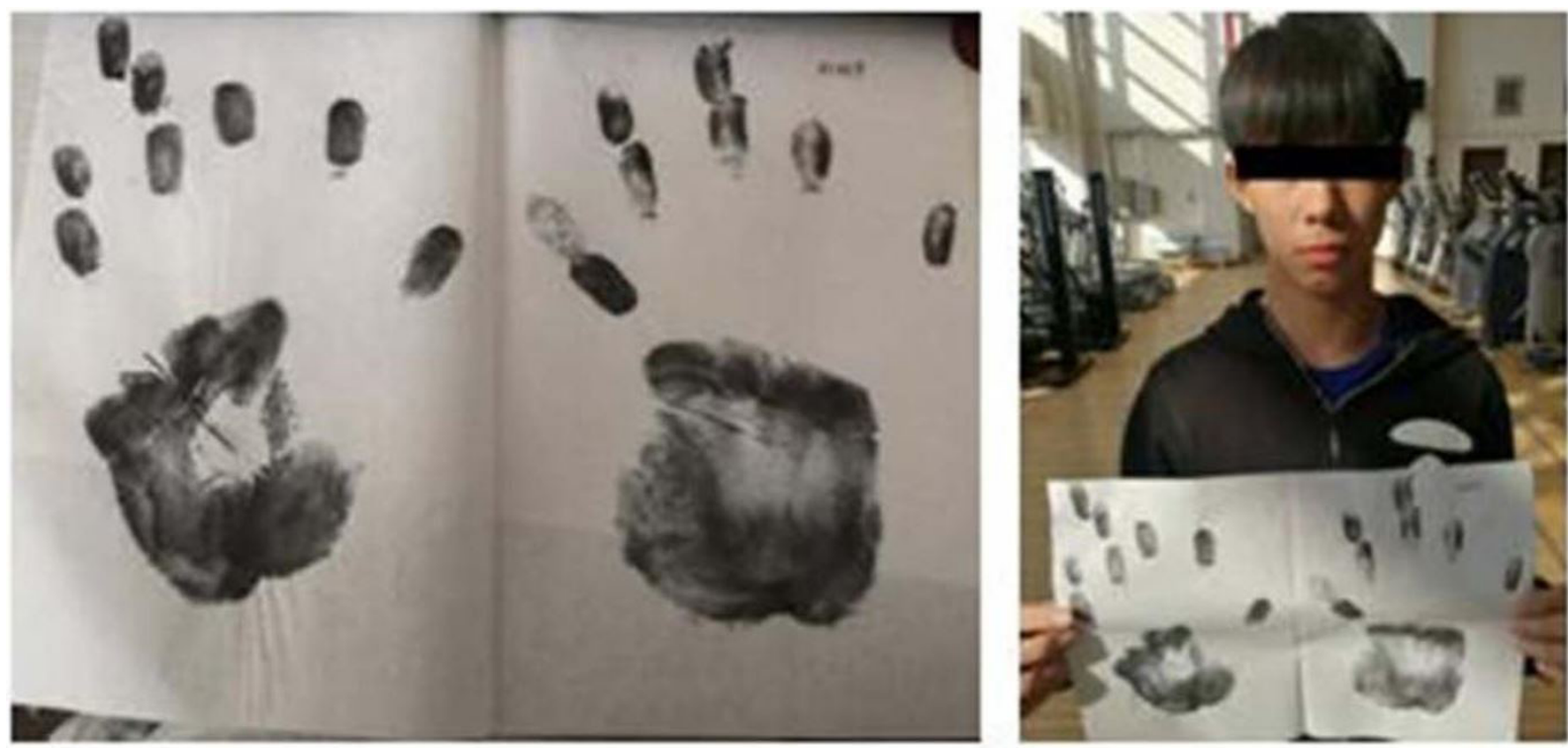

Figure 4. The handprints of the dermatoglyphy of one of China's elite table tennis player. 


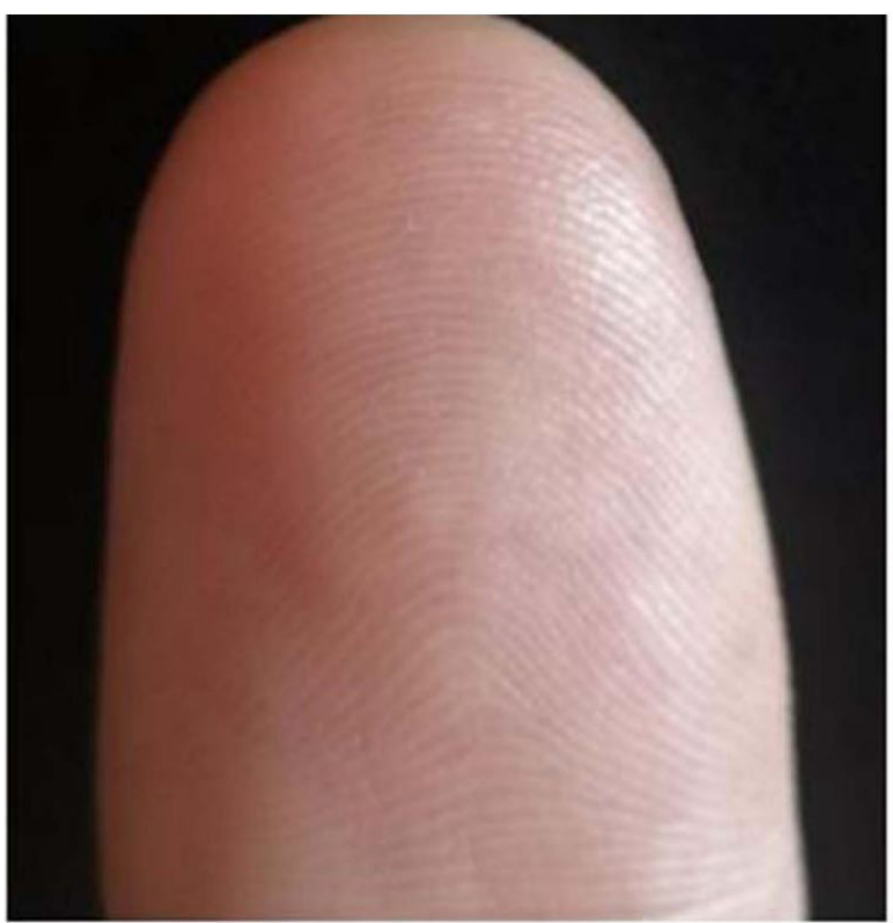

Figure 5. Flat arch (first image); and tented arch (second image).

mainly used to reflect the body's quality of continuous working and resistant to physical fatigue, relating to the circulatory system, respiratory system and nerve types of the body. It is well acknowledged that table tennis competition takes a long duration time and generally involves many rounds, each goal needs the joint output of technology, tactics and mentality. In this regard, strong endurance quality constitutes a perquisite for athletes to reach the highest level in the key points and the deciding game. Considering the greater intensity of the competition, it is also necessary for athletes to have strong muscle endurance support to ensure the stable performance of athletes during the competition.

As shown in Table 5, no significant difference was found in the number of arch pattern between the excellent group and ordinary group $(p>0.05)$.

\subsection{Double loop whorl}

Double loop whorl is formed by two entwined loop patterns (Figure 6), the associated openings walk in the opposite direction, and each pattern has one trifurcation point and center. The number of double loop whorl represents the coordinate and sensitive quality of the athletes (Limoochi, 2005). Among the various physical abilities, the coordination training is the most difficult. The number of double loop whorl is hereditydependent to some extent, and higher number means better coordinate quality. The occurrence rate of this kind dermatoglyphy accounts for $30 \%$ in ordinary people, while it is $45-60 \%$ among the athletes in various kinds of sports (Wu, 2006). As shown in Table 6, there is a great significant difference in the number of double loop whorl between the excellent group and ordinary group (2.58 \pm 1.676 vs $0.92 \pm 0.669, p<0.01)$, indicating that

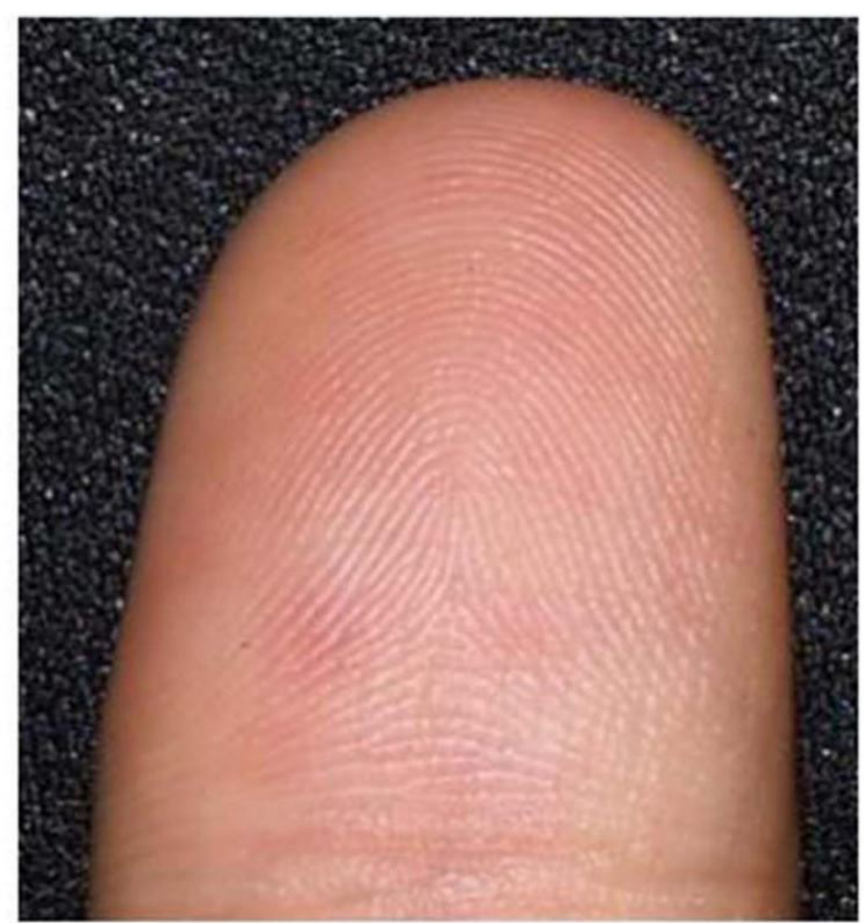

Table 5. The comparison of arch pattern between excellent group and ordinary group.

\begin{tabular}{cccccc}
\hline Group & $\mathrm{N}$ & $\mathrm{M} \pm \mathrm{SD}$ & $\mathrm{T}$ & $\mathrm{SIN}$ & $P$ \\
\hline Excellent & 26 & $0.72 \pm 0.850$ & -1.374 & 0.021 & $>0.05$ \\
Ordinary & 66 & $0.85 \pm 1.139$ & & & \\
\hline
\end{tabular}

Table 6. The comparison of double loop whorl between excellent group and ordinary group.

\begin{tabular}{cccccc}
\hline Group & $\mathrm{N}$ & $\mathrm{M} \pm \mathrm{SD}$ & $\mathrm{T}$ & $\mathrm{SIN}$ & $P$ \\
\hline Excellent & 26 & $2.58 \pm 1.676$ & 3.199 & 0.004 & $<0.01$ \\
Ordinary & 66 & $0.92 \pm 0.669$ & & & \\
\hline
\end{tabular}

the coordinate quality of the athletes in excellent group is better than that of ordinary group.

\subsection{Loop pattern}

Loop pattern is a kind of real dermatoglyphy with one trifurcation point, the lines of which move from one side of the finger to the middle, slanti upward and back to the same side. According to the opening direction, it is divided into ulnaris loop and radialis loop (Figure 7). The number of such dermatoglyphy, which is common among ordinary people, can partly reflect the flexibility quality of an athlete's body (Wang, 2000). The more loop pattern represents the better flexibility quality. In this study, we found that there is no significant difference ( $p>0.05$, Table 7$)$ in the number of loop pattern between the excellent group $(3.82 \pm 2.570)$ and ordinary group $(3.67 \pm 1.850)$. These findings reveal that there is no statistical difference in the physical flexibility of athletes between the excellent group and the ordinary group. 

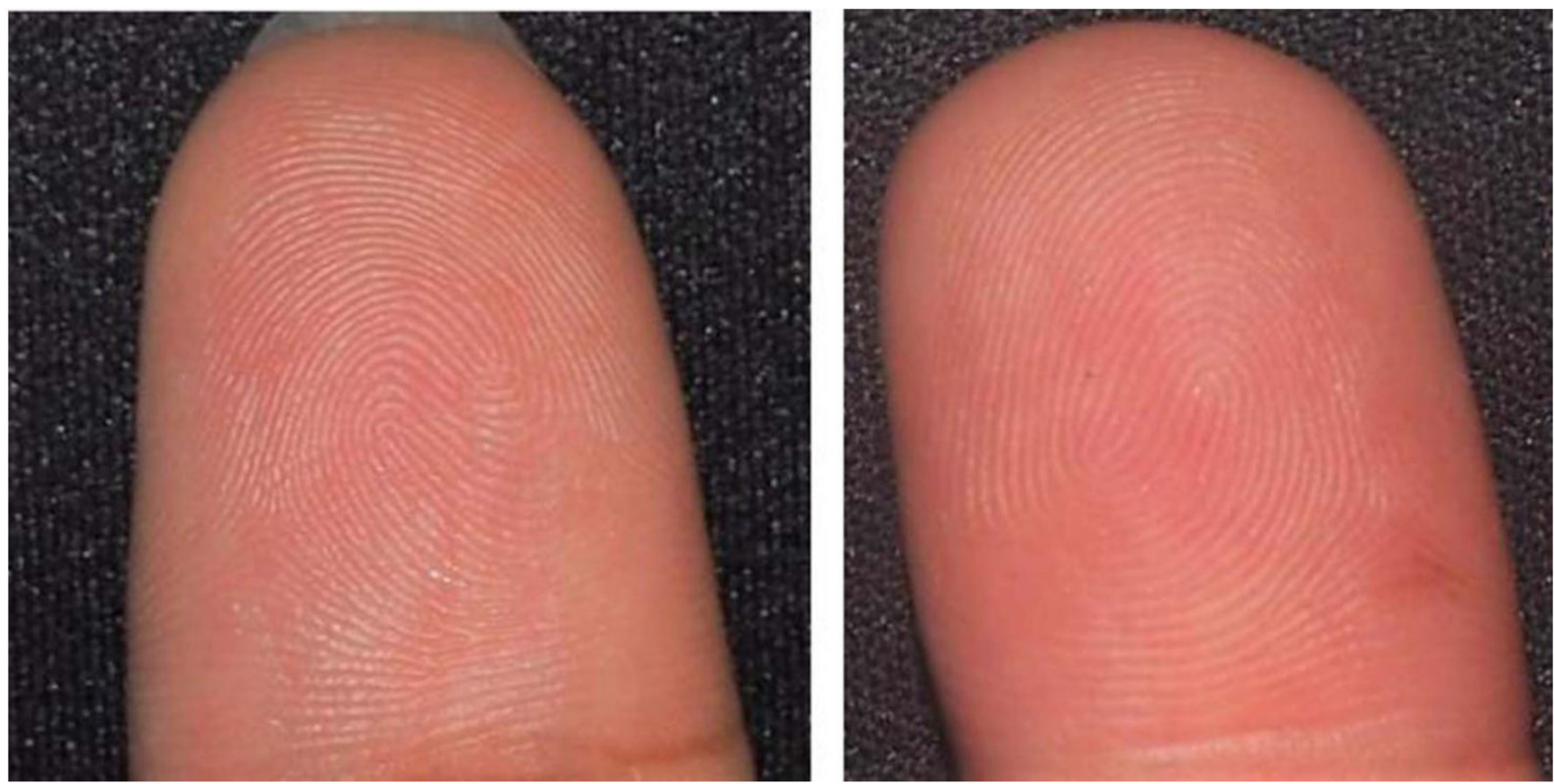

Figure 6. Typical double loop whorl.
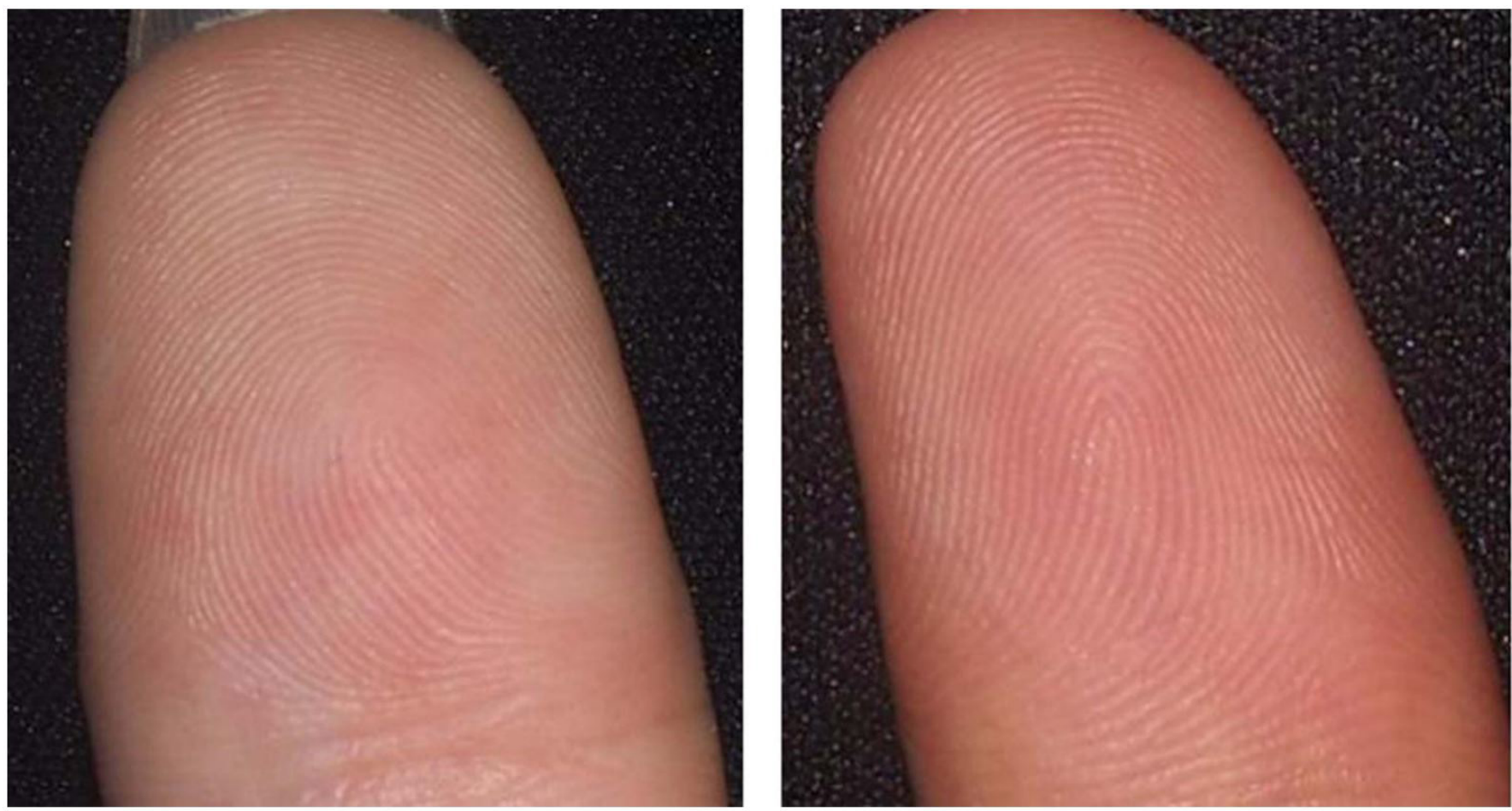

Figure 7. Loop pattern. Left-hand ulnaris loop (first image); Right-hand radialis loop (second image).

In summary, our dermatoglyphic analyses in this study suggest that Chinese high-level professional table tennis players generally share beneficial attributes for advanced sport performance in terms of table tennis, including high mental level, excellent speed quality and coordination quality. On the other hand, the
Table 7. The comparison of loop pattern between excellent group and ordinary group.

\begin{tabular}{cccccc}
\hline Group & $\mathrm{N}$ & $\mathrm{M} \pm \mathrm{SD}$ & $\mathrm{T}$ & $\mathrm{SIN}$ & $P$ \\
\hline Excellent & 26 & $3.82 \pm 2.570$ & -0.182 & 0.857 & $>0.05$ \\
Ordinary & 66 & $3.67 \pm 1.850$ & & & \\
\hline
\end{tabular}


strength quality, endurance quality and flexibility quality are not outstanding in comparison with ordinary players. The combined findings pave a feasible way for selecting elite table tennis athletes using dermatoglyphic analysis.

\section{Ethical approval}

All procedures performed in studies involving human participants were in accordance with the ethical standards of the institutional and/or national research committee and with the 1964 Helsinki declaration and its later amendments or comparable ethical standards. This study is approved by relevant Ethics Committee.Written informed consent was obtained.

\section{Conflict of interest}

The authors declare that they have no competing interest.

\section{Availability of data and material}

The datasets used or analysed during the current study are available from the corresponding author on reasonable request.

\section{Funding}

This work was supported by the National Social Science Fund of China (20BTY040), Social Science Foundation of Liaoning Procince (L18DTY004) and the 13th Five-Year Education Program of Liaoning Province (JG18JD298).

\section{Author contributions}

Xin Deng was dedicated to the integrity of the entire study, study concepts, manuscript editing and manuscript review. Chao Zheng and Xin Deng focused on the literature research, data analysis. Yilun Gao and Ye Zhang was involved in the experimental studies, data acquisition and statistical analysis. Feng Tai and Yilun Gao carried out the study design, definition of intellectual content, manuscript preparation and manuscript editing. All authors have read and approved this article.

\section{References}

Abbott, A., Button, C., Pepping, G. J., \& Collins, D. (2005). Unnatural selection: talent identification and development in sport. Nonlinear Dynamics, Psychology, and Life Sciences, 9(1), 61-88. PMid:15629068.

Ahmed-Popova, F. M., Mantarkov, M. J., Sivkov, S. T., \& Akabaliev, V. H. (2014). Dermatoglyphics--a possible biomarker in the neurodevelopmental model for the origin of mental disorders. Folia Medica, 56(1), 5-10. http://dx.doi.org/10.2478/folmed-2014-0001. PMid:24812916.

Amaral, D., Cardelle-Cobas, A., Dias, C., Lima, D. A. S., Pereira, S. F., Arcanjo, N. M. O., Dalmás, P. S., Madruga, M. S., \& Pintado, M. M. E. (2020). Low fat goat meat sausage with chitosan-glucose Maillard reaction product: impact on quality and shelf life. Food Science and Technology, 40(1), 132-139. http://dx.doi.org/10.1590/fst.34018.

Borin, J. P., Padovani, C. R., Aragon, F. F., \& Gonçalves, A. (2012). Dermatoglyphics in Sports Sciences: understanding the distribution of quantitative indicators in non-athletes and athletes of basketball according to their performance. Revista Andaluza de Medicina del Deporte, 5(3), 99-104. http://dx.doi.org/10.1016/S1888-7546(12)70015-1.
Fournier, N. A., \& Ross, A. H. (2016). Sex, ancestral, and pattern type variation of fingerprint minutiae: a forensic perspective on anthropological dermatoglyphics. American Journal of Physical Anthropology, 160(4), 625-632. http://dx.doi.org/10.1002/ajpa.22869. PMid:26397817.

Ho, Y. Y. W., Evans, D. M., Montgomery, G. W., Henders, A. K., Kemp, J. P., Timpson, N. J., Pourcain, B. S., Heath, A. C., Madden, P. A. F., Loesch, D. Z., McNevin, D., Daniel, R., Davey-Smith, G., Martin, N. G., \& Medland, S. E. (2016). Genetic variant influence on whorls in finger patterns. The Journal of Investigative Dermatology, 136(4), 859-862. http://dx.doi.org/10.1016/j.jid.2015.10.062. PMid:27045867.

Johnston, K., Wattie, N., Schorer, J., \& Baker, J. (2018). Talent identification in sport: a systematic review. Sports Medicine, 48(1), 97-109. http:// dx.doi.org/10.1007/s40279-017-0803-2. PMid:29082463.

Karaagac, H. E., Cavus, F., Kadioglu, B., Ugur, N., Tokat, E., \& Sahan, Y. (2021). Evaluation of nutritional, color and volatiles properties of currant (Ribes spp.) cultivars in Turkey. Food Science and Technology, 41(2), 304-313. http://dx.doi.org/10.1590/fst.29119.

Lakshmana, N., Nayyar, A. S., Pavani, B. V., Ratnam, M. V. R., \& Upendra, G. (2017). Revival of dermatoglyphics: syndromes and disorders, a review. Advences in Human Biology, 7(1), 2-7. http:// dx.doi.org/10.4103/2321-8568.199528.

Li, X. H., \& Ji, K. P. (1995). Anatomical basis and application of human dermatoglyphics. Zhongguo Yousheng Yu Yichuan Zazhi, 12(2), 52-55.

Limoochi, S. (2005). Investigation of coaches'opinions on table tennis selection criteria. Sports Scientific Research, 26(3), 105-107.

Maluly, H., Johnston, C., Giglio, N. D., Schreiner, L. L., Roberts, A., \& Abegaz, E. G. (2020). Low- and No- calorie Sweeteners (LNCS): critical evaluation of their safety and health risk. Food Science and Technology, 40(1), 1-10. http://dx.doi.org/10.1590/fst.36818.

Oliveira, G. L., Oliveira, T. A., Valentim-Silva, J. R., \& Fernandes, J. Fo. (2018). Dermatoglyphic profile and body composition of athletes from the Brazilian five-a-side national football team. International Journal of Sports Science, 8(3), 78-82.

Priyadarshini, P. A., Bindu, S., Siddiqa, R., Yogish, R., Aithal, M., \& Sadiya, H. (2016). Dermatoglyphic variation, as genetic markerson plantarsurface: potentiality for sports men. International Journal of Pharmaceutical, Chemical and Biological Sciences, 6(2), 251-256.

Qiu, Y. (2015). Study on dermatoglyphic characteristics and selection of Chinese female Sanda athletes. Liaoning: Liaoning Normal University.

Serhiyenko, L. P., \& Lyshevska, V. M. (2013). Soles dermatoglyphics in the prognosis of sports endowment: differences of soles dermatoglyphics in sportsmen of different sport kinds. Pedagogics, Psychology, Medical-Biological Problems of Physical Training and Sports, 3, 57-61.

Shao, Z. (1992). Dermatoglytics and athletes selection. Acta Anthropologica Sinica, 11(4), 369-374.

Shao, Z. W. (1989). Dermatoglyph and material selection. Beijing: People's Sports Publishing House.

Tian, M. C. (2006). Sports Training. Beijing: Higher Education Press.

Wang, D. X. (2000). On the selection and management of children table tennis players. Anhui Sports Science and Technology, 3, 60-62.

Wang, J. C. (2005). Present situation and prospect of Chinese table tennis players selection. Journal of Wuhan Institute of Physical Education, 39(9), 82-84.

Wang, J. C. (2006). Principles and methods of sports material selection. Beijing: People's Publishing House.

$\mathrm{Wu}, \mathrm{C}$. (2006). Talking about the selection of basic table tennis players. Mudanjiang Normal University Journal, 4, 43-44. 
Yu, W. Q., \& Tai, F. (2012). Research on dermatoglyphics characteristics of tennis players-a case study of tennis players in Liaoning province. China Sport Science and Technology, 48(6), 30-34.
Zhang, Y., \& Li, M. (2008). Feasibility analysis of selecting athletes by using the dermatoglyphic characteristics of U-shaped venue snowboarders. Journal of Harbin Institute of Technology, 4, 17-21. 


\section{Supplementary material}

Supplementary material accompanies this paper.

Table S1. The mental state of some elite athletes in China.

This material is available as part of the online article from

http://www.scielo.br/cta 